\title{
Conflict on multi-national construction projects
}

R. Fellows PhD, FRICS, FCIOB, MCIArb and A. Liu MSc, PhD, FRICS, FHKIS

By definition, multi-national construction projects bring together organisations and individuals from different countries and, therefore, almost inevitably, different cultures. As cultures underpin behaviour and behaviour has major impacts on performance - both what is desired and what is realised - issues of cultural compatibility between project participants are important. A further aspect relates to attitudes to conflict and thence disputes regarding their likelihood, causes and consequences - in essence, how they may be managed. This paper aims to critically review the theory and literature regarding cultures and to examine their relevance to selection of multi-national project participants, management of conflict and resulting outcomes for project performance and participant satisfaction. Of particular note are aspects of cultural compatibility/cultural distance for both selection of project participants and resultant performance.

\section{INTRODUCTION}

While some projects enjoy wide publicity of their success and enhance research in critical success factors for construction procurement (Parfitt and Savindo, 1993; Pinto and Slevin, 1998; Westerveld, 2003), lessons can be equally learnt from less successful projects fraught with conflict due to cultural incompatibility. Researchers and government reports (Latham, 1994) allege that the construction industry is perceived to have a culture of conflict (Langford and Murray, 2008; Rooke et al., 2003). Disputes on projects can destroy relationships (Fenn, 2008); project performance is consequently reduced and dissatisfaction ensues (in which all participants apportion blame and seek redress from contract provisions). A variety of initiatives have been invoked in attempts to address such problems (e.g. design and build procurement and the New Engineering Contract).

A central tenet of this paper is that it is essential to address the business imperatives of organisations (especially profitability and growth) in conjunction with the technical particularities relating to construction procurement, recalling that outcomes can be achieved only via people within a context of social institutions comprising both formal and informal systems that shape behaviour and performance. Social systems embed potential inter-personal and organisational conflict.

Increasing specialisation/division-of-labour not only indicates differing areas of expertise, but also suggests diverging interests, values and objectives. Coordination and cooperation are required for the realisation of construction projects given the likely perceived conflict of interests between joint and individual costs and benefits. However, depending on the level and unit of analysis, there is much in the literature to indicate that conflict may have significant positive effects (Robbins, 1984; Schmidt, 1974) that concern the performance of tasks and the development of relationships.

Furthermore, the typology of personal/organisational conflicts (van de Vliert, 1998; Yuen, 1992) implicitly adopts the perspective of organisational identity and behaviour beyond those of the individuals comprising the organisation (i.e. its members rather than its stakeholders). However, there is not a great array of literature examining conflict by addressing differences between the natures of different societies - that is, their cultures. The aim of this paper is to review the literature regarding culture and to examine its relevance to the selection of multi-national project participants, and the management of conflict and resulting outcomes for project performance and participant satisfaction. Of particular note are aspects of cultural compatibility/cultural distance for both selection of project participants and resultant performance.

\section{CONFLICT}

According to van de Vliert (1998)

Two individuals, an individual and a group, or two groups, are said to be in conflict when and to the extent that at least one of the parties feels it is being obstructed or irritated by the other.

More popularly, conflict is (Deutsch, 1973) '... incompatible behaviour between parties whose interests differ'.

There are "conflicts of interest between vertical participants in supply chains, just as there are between those competing horizontally' (Cox, 1999). In a capitalist business context, there are opportunistic endeavours to appropriate a greater share of a finite total benefit for the self; however, 'only by having the ability to appropriate value from relationships with others ... can business be sustained' (Cox, 1999).

A common theme in the array of definitions of conflict is anticipated or actual frustration of one actor perceived by that actor to be caused by the actions or inactions of another(s), which impacts on the former's potential outcomes - often couched in terms of goal attainment (McKenna, 2000). Thus, the presence of conflict arises from negative feelings. 
Within management teams, conflict may be classified as cognitive (regarding intellectual/technical issues) or affective (concerning subjective/emotional aspects) (Amason et al., 2000). Such typology is reflected in much of the pragmatic conflict resolution literature, which advocates a focus on cognitive issues to achieve resolution due to the negative/blocking/destructive potential of the affective aspects (Fisher and Ury, 1991).

Conflict may be classified in terms of its effects - either functional/constructive or dysfunctional/destructive (Yuen, 1992). Functional conflict, somewhat akin to competition (i.e. actors have a common objective, even if the outcome is of a win-lose form as in construction bidding), is believed to stimulate ideas, innovation, etc. because it is regarded as a motivator. Dysfunctional conflict, however, yields the wellknown consequences that are detrimental to relationships and technical performance.

There are three main perspectives on conflict.

(a) The traditional, functionalist perspective regards conflict negatively - as disruptive and thus harmful.

(b) Behaviourists are neutral, regarding conflict between individuals and groups as inevitable and believing that differences in the consequences of conflict arise through differences between people - their perceptions, personalities, interests/expertise and goals.

(c) Interactionists view conflict as carrying out useful functions to ensure social dynamism and to enhance decisions; however, the conflict, including the amount of conflict, must be managed (Yuen, 1992).

Generally, sources of conflict tend to follow the classification of communication, structure and personal factors (Robbins, 1974). In addition to the well-known communications issues that may give rise to conflict - semantic differences, difficulties, insufficient or excess information, noise and filtering of information (distortion, withholding, etc.) - other aspects including indexicality (Clegg, 1992), choice of channel(s) and the nature of the language (high content-high context) impact. Structural factors comprise size and constituent members of the group, ambiguity, leadership, rewards, interdependency and changes to structure and/or processes. Personal factors include personality characteristics (traits, etc.) and peoples' value systems (fundamentals of culture).

Various models of the conflict process have been advanced notably the bargaining model, the bureaucratic model and the systems model which was developed to produce the episodic model (Pondy, 1967). A further alternative is the escalation (and de-escalation) model (van de Vliert, 1998). These models acknowledge that conflict incidents (episodes) are not individual isolated events but cycle iteratively: each episode has antecedents and quite enduring consequences, the latter impacting on persons' dispositions and thus inputting to antecedents for future conflict episodes, the subject(s) of which may be proximate or distant. The escalation/de-escalation perspective is determined by how an episode is managed and so yields the nature of an episode's consequences as future antecedents.

Generally, five generic styles of conflict management (handling/ coping) are considered: (a) avoiding (unassertive and uncooperative)

(b) competing (assertive and uncooperative)

(c) collaborating (assertive and cooperative)

(d) accommodating (unassertive and cooperative)

(e) compromising (mid-assertive and mid-cooperative).

These styles fill the two-dimensional space of conflict management between axes of assertiveness and cooperativeness (Thomas, 1992). Avoiding involves suppression of the conflict matter or/and withdrawal so that the conflict matter is not addressed and may remain dormant or festering for others to resolve. Competing takes the form of a zero-sum game in which self-interests may be pursued aggressively by the use of authority, power, etc. Collaborating seeks to follow mutuality in seeking a solution to yield a non-zero-sum game and to preserve or even enhance relationships by striving together for a solution. Accommodating resembles appeasement by subjugating self-interests to those of the other(s), which tends to take the form of a zero-sum game. Compromising, again, seems to be a zero-sum game of give and take to yield a solution of balanced gains and losses for each party.

Conflict behaviour, then, is a person's outward reaction to the conflict that is felt/perceived; the components of such behaviour are thus interrelated, as noted by Euwema and van Emmerik (2007)

Interpersonal conflicts really are complex situations in which different motives and concerns about own goals, the reaction with the other, other's goals, as well as short and long-term objectives, direct behaviour...

Conflicts arise between, and are resolved by, people. Identifying and pursuing a super-ordinate goal(s) is effective in resolving inter-group conflict - the groups identify a common problem that dominates and, to resolve it, cooperation between them is required. However, significant disparity in the distribution of power between the groups may preclude such resolution (Sherif, 1967).

Given the likely performance-depleting effects of affective conflict but the potential performance enhancement through good management of cognitive conflict, managers should endeavour to prevent affective conflict while recognising the great potential for the conflict types to become mixed in practice. For such management of people to be possible, comprehension of the cultures that led to the behaviour and communications giving rise to the conflict is essential.

\section{CULTURE}

Most early work on culture flourished in the fields of anthropology, sociology and organisational psychology. For instance, there are two anthropological views in which one perceives culture as observed patterns of behaviour that are exhibited by members of a community (therefore culture is situated outside the individual and is considered as something that is directly observable within the organisation) and the other explains culture as that which is shared in members' minds, sometimes including the invisible unstated parts of culture (Sathe, 1983).

Simplistically, culture is 'how we do things around here' (Schneider, 2000). However, the scope is much more extensive to include what is done, why things are done, when they are 
done and by whom. Thus, culture may be defined as '... the collective programming of the mind which distinguishes one category of people from another' (Hofstede, 1994a). Cultures comprise the beliefs, values and norms that are shared by members of a community and adopted by them through socialisation and education. Models of culture often depict physiological instincts and beliefs at the core (survival imperatives, religion, morality, etc.), values as the intermediate layer (the hierarchical ordering of aspects of beliefs, perhaps with visions of trade-offs) and behaviour as the outer layer of cultural manifestations (as in language, symbols, heroes, practices, artefacts, etc.). According to Trompenaars and Hampden-Turner (1997)

... beliefs are statements about reality that individuals accept as true, values are generalised principles of behavior to which people feel strong positive or negative emotional commitment, and norms are shared rules of standards regarding the extent to which specific behaviors are to be considered socially acceptable...

Given the nature of the major components of culture typology, it is clear that variability within determined cultural boundaries (e.g. geographical) may be large, especially at the surface of manifestations (behaviour, norms, etc.).

There exists an array of sets of dimensions that are variously employed to measure culture (national/organisational); many of the metrics are intended to yield relative measures on the dimensions. Five value-oriented dimensions of culture have been suggested to '... greatly influence our ways of doing business and managing as well as our responses in the face of oral dilemmas' (Wagner and Moch, 1986). These dimensions are:

(a) universalism-particularism (rules-relationships)

(b) collectivism-individualism (group-individual)

(c) neutral-emotional (feelings expressed)

(d) diffuse-specific (degree of involvement)

(e) achievement-ascription (method of giving status).

Hofstede (1980) determined four dimensions for national cultures: power distance, individualism/collectivism, masculinity/femininity and uncertainty avoidance. A fifth dimension of long-/short-termism was added later (Hofstede, 1994b) following studies in Asia that found important impacts of 'Confucian dynamism' (CCC, 1987).

However, there have been various critiques (and constructive comments) directed at Hofstede's empirical work on IBM employees (McSweeney, 2002; Roberts and Boyacigiller, 1984). Others (e.g. Smith (2002)) acknowledge the tenacity with which Hofstede (2001) tracks his critics' work to reanalyse published data showing that the 'accused' deficiencies are a consequence of failure to take account of cultural differences in acquiescent response bias. There is no doubt that Hofstede's work has sparked a stream of validating studies: on power distance (House et al., 1999); on uncertainty avoidance (Chan et al., 1996; Helmreich and Merritt, 1998; Hoppe, 1990); on individualism (Schwartz and Sagie, 2000; Singelis, 1994) on masculinity (Buss et al., 1990; Kashima et al., 1995); and on long-termism (Noorderhaven and Tidjani, 2001).

Given the content of the enduring debate, it seems appropriate to regard the resulting measurements as indicators rather than absolute accurate quantifications. That perspective is extended by the recognition that within-group variances frequently exceed between-group variances - a vital consideration in comparative analyses (Au, 2000).

There are two primary levels of culture analyses - national and organisational level. Although the dimensions employed for assessing culture differ between the two categories (Hofstede, 1980, 2001) because superficial manifestations must be addressed for such assessments, the fundamental underpinnings in beliefs and values apply to both. Furthermore, organisational culture is embedded in the national culture of the organisation's domestic location - an increasingly fuzzy perspective with internationalisation and globalisation - as well as being impacted by the institutional environments in which it has operated (Oliver, 1997).

There are significant differences among researchers regarding how organisational culture should be assessed (Meek, 1988). One group of researchers believes that culture is something an organisation has and can be regarded as an independent variable in causal relationships; the other group argues that culture is something an organisation is. In general, it is agreed that organisational culture

(a) is a multi-faceted construct (Pettigrew, 1979)

(b) reflects customary thoughts, feelings and acts that are attributed to a particular group of people as they learn to cope with their environment (Deal and Kennedy, 1982; Ouchi, 1981) and involves cognition, affect and behaviour (Ott, 1989)

(c) is both learned and transmitted (Schein, 1985)

(d) is an abstraction from behaviour as well as a product of behaviour (Davis, 1985; Quinn, 1988).

This does not, however, provide enough detail for accurate measurement of organisational 'culture'. Others have developed cultural dimensions in the conceptualisation of culture types (Ansari et al., 1982; Chatman and Jehn, 1994; Hofstede et al., 1990).

Hence, there are two basic approaches to studying organisational culture - the typological approach (cultural types) and the trait approach (cultural dimensions). As in the case of conceptualisation of culture, there is little agreement on the way to categorise cultural types. A useful and measurable typology of culture distinguishes three types of organisational culture: bureaucratic, innovative and supportive (Wallach, 1983). Other categorisations are available from the domains of risk taking and feedback to centralisation and decentralisation of power (Deal and Kennedy, 1982; Hood and Koberg, 1991; Quinn, 1988). Apart from the conceptualisation of types of culture, there have also been various studies in the dimensions of culture from different perspectives such as sociopsychological (Ansari et al., 1982), technological (Chatman and Jehn, 1994), and socio-structural (Hofstede et al., 1990; Reynolds, 1986). It is found that career success and satisfaction is a function of the fit of a manager's personal orientation with culture in the organisation (Ansari et al., 1982) and that culture can be measured as a multi-dimensional set of values and practices embraced by the organisation (Hofstede et al., 1990).

Scrutiny of the various dimensions used to analyse both national and organisational cultures indicates considerable 
conceptual commonality. There are many ways of categorising organisational dimensions (Cameron and Quinn, 1999; Hofstede, 1994b). Hofstede (1994b) proposes six dimensions of organisational cultures

(a) process-results orientation

(b) job-employee orientation

(c) professional-parochial

(d) open-closed system

(e) tight-loose control

(f) pragmatic-normative.

Alternatively, a competing values model, which yields four types of organisational culture - clan, adhocracy, market, hierarchy - has been suggested (Cameron and Quinn, 1999).

Hofstede's dimensions of organisational culture align with the human relations-task schools of management thought, for example theory $X$ and theory $Y$ (Herzberg et al., 1967). Notably, organisational cultures are embedded within the national culture of the home country and hence manifestations along dimensions of organisational culture are underpinned by, and embedded in, those pertaining to national culture. Organisations may not exhibit a single unitary culture and measures used for strengths of cultures are subject to significant questioning (Cameron and Quinn, 1999). However, others assert that every successful organisation has a core culture (control, collaboration, competence, cultivation) that is central to its functioning (Schneider, 2000).

Cultures evolve in path-dependent directions, punctuated occasionally by periods of stability and rapid step-type changes: 'the evolution of culture is shaped by agency and power' (Weeks and Gulunic, 2003). However, '... despite agreement that cultural evolution occurs ..., espoused approaches to culture interventions are more commonly revolutionary in nature ...' (Harris and Ogbonna, 2002). When faced with change, most people exhibit strong preference for the familiar and so tend to resist; if change does occur, there is a strong tendency to revert to prior norms.

Perspectives on changes in cultures span two extremes. Functionalists believe that organisational culture can be controlled by management directly and are thus instrumental in promoting the cultural basis for determining organisational performance. The alternative perspective regards culture as a context within which action must be taken, and so necessitates compatibility of action with the cultural environment. A third category is the perspective that culture is malleable and may be adapted, albeit that adaptations are likely to be difficult and require effort over long periods. However, even the most carefully devised and conducted change initiatives are likely to have unanticipated consequences - including ritualisation of change, cultural erosion, hijacking of the process, and uncontrolled and uncoordinated effects (Harris and Ogbonna, 2002).

Thus, cultural sensitivity towards the people affected and the processes and norms of their behaviour and operations is required in order that initiatives that are intended to aid the situation through enhancing relationships and performance are not themselves significant contributors to detrimental outcomes.

\section{CONSTRUCTION PROCUREMENT}

\section{I. Project participants}

In construction, a vital consideration is the impact of culture on what performance is achieved and measured against predetermined, culturally bound, targets. Those targets are determined by project participants and depend upon their values within the project realisation as undertaken by a temporary multi-organisation (TMO) with a significantly transient membership of both individuals and organisations.

Traditionally, issues regarding the workings of a TMO (TIHR, 1966) stem from its nature (temporariness, diverse membership and fluid power structuring) and context (operating in a capitalist market environment). Given the membership of a TMO, its nature is of an alliance form, wherein relationships impact on performance and are determined by objectives (congruence), risk, trust, culture, etc. The temporariness in a TMO suggests that transient relationships foster self-oriented, opportunistic behaviour.

This paper acknowledges that performance is achieved through the informal system (TIHR, 1966) of generic functional perspective depicted in Figure 1. Performance leads to the satisfaction of participants and hence (perspectives of) project success. Performance-satisfaction-success also produces feedforward in the 'cycling' of project data and information to aid realisations of future projects through participants' perception-memory-recall filtering ('experiences').

When performance is reported as falling significantly below expectations, reasons proffered often include inadequate briefing, poor design, lack of productivity in the construction process, lack of constructability, poor coordination, lack of skill, institutional/regulatory framework and claims (Green and Simister, 1999; Rooke et al., 2003). Although value management and value engineering have been employed on some projects, their specialist application, beyond cost planning by quantity surveyors, has not been extensive. Where valueoriented analytic methods have been applied, they tend to adopt a single-participant perspective (usually relating to the commissioning client) and to freeze the value hierarchy at the time of executing the study at a particular stage in project realisation - often, later in the design phase than desirable (Green and Popper, 1990; Kelly et al., 2004).

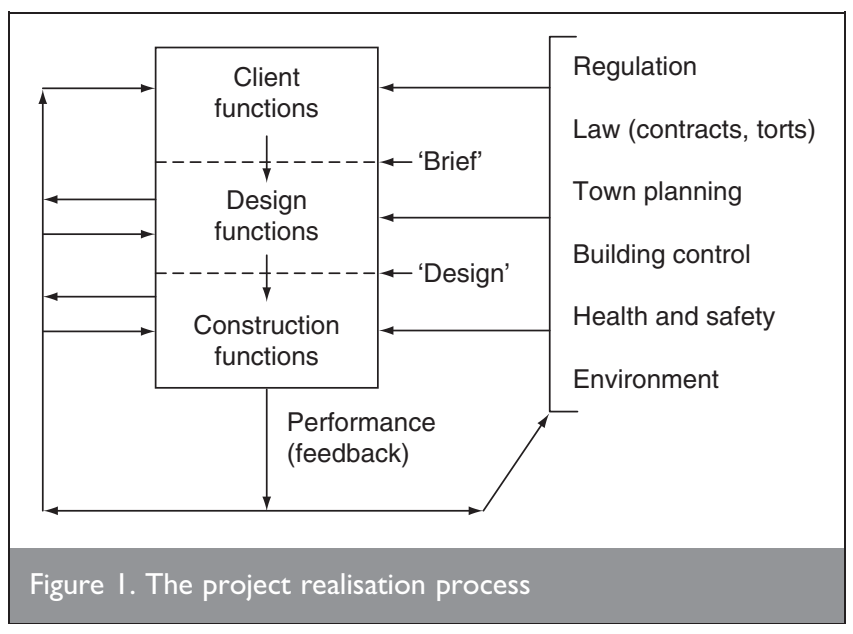


However, even if value structures (values of the commissioning client) are accurately determined for briefing, the likelihood of powerful others imposing their own value structures on the project during realisation is likely to yield outcomes different from those determined initially. As noted by Ireland (2004) '... clients ... do not always fully understand their demand profile ... construction companies are effectively the 'integrator' for a myriad of construction supply chains ... Adversarialism and opportunism are rife at all stages ....

Often, project participants are selected by the commissioning client and 'close advisors' irrespective of the procurement approach. In the pre-selecting of project participants, the criteria remain firmly founded in the perceived technical expertise/ capability of the organisations and the ability of the organisations to integrate and cooperate to work together to deliver the project effectively and efficiently (Baiden et al., 2006). Five categorical factors have been suggested to be critical to success and superior performance of cross-functional teams task design, group composition, organisational context, internal processes and group psycho-social traits (Nicolini, 2002). These factors are important contributors to 'project chemistry' and 'project affinity', which comprise a range of antecedent variables necessary for project management success (Dainty et al., 2005).

However, within price bidding by pre-selected contractors, it is common for opportunistic approaches to submit the lowest acceptable bid but incorporate the potential for future price and profit enhancement (Rooke et al., 2003, 2004). Such opportunism includes 'variation spotting', 'claims potential' and 'bid loading' (usually front-end) (Fellows et al., 2002). Further manipulations include endeavours to overvalue interim payments. In respect of cost reducing means of enhancing profit, contractors have employed 'pay-when-paid' provisions, late payments (unilateral extensions of credit), deducting discounts illegitimately and 'Dutch auctioning'/'bid shopping' with subcontractors and suppliers. All such business ploys are likely to invoke conflict. Although some jurisdictions are legislating to prevent such actions, they remain widespread.

\subsection{Project culture framework}

Increasingly, multi-national projects are undertaken through formal alliances between the primary participants. However, even if no formal alliance is executed, the interdependence between the activities of the participants requires informal alliancing. Uncertainty and trust are the two primary constructs that affect formal alliance relationships and their institutional arrangements (Sheth and Parvatiyar, 1992). Strong institutional arrangements have been demonstrated to foster the development of trust; otherwise, business actors resort to power to safeguard their interests - through actual or perceived potential conflict and outcomes thereof.

Trust is always an element in the decision to engage in a (business) relationship, whether the source(s) of trust is founded in legal/contractual mechanisms, institutions (Bachmann, 2001; Hagen and Choe, 1998) or individuals - singly or in combination. Cooperation is 'coordination effected through mutual forbearance' (Buckley and Casson, 1995). Trust is 'a willingness to rely on the actions of others, to be dependent upon them, and thus be vulnerable to their actions' (Swan et al.,

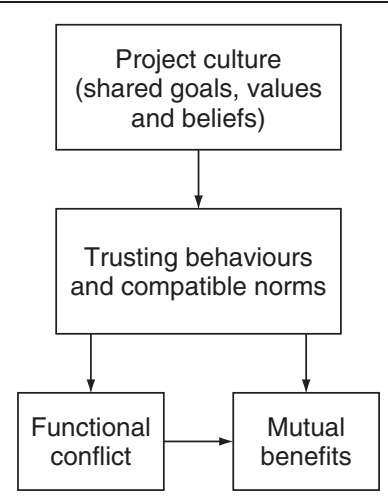

Figure 2. Project culture

2008); trust thus 'affects the willingness to cooperate' (Wood and McDermott, 1999). Trust may be considered to be adequate confidence on the part of the subject actor/participant that the other participant(s) will not cheat. This is distinct from assurance, which is provided through constraints imposed by a formal framework (e.g. contract provisions).

Considering the significance of culture, conflict and trusting behaviours, a project culture framework is proposed in Figure 2. According to Doney et al. (1998)

Since each culture's collective programming results in different norms and values, the processes trustors use to decide whether and whom to trust may be heavily dependent on a society's culture.

Some UK reports (CAG, 2001; Egan, 1998) have expressed doubt over the existence of positive values in the construction industry. However, at project level, there are examples of trusting behaviour in successful projects. Hence, according to Swan et al. (2008) it is

clear that while social values and norms are important, organisational, project and individual values must be considered when assessing the social structure of an organisation. Two organisations with radically different cultures may not be in a situation to create the glue of shared norms and values.

A project trust culture is important in nurturing and enhancing cooperative behaviours amongst organisations and individual participants so that functional conflict is properly managed for the mutual benefit of all.

\section{DISCUSSION}

It is widely acknowledged that once conflict is aroused (the episode becomes manifest) it is difficult to control (van de Vliert, 1998; Yuen, 1992). Such difficulties are likely to expand geometrically in multi-cultural settings according to cultural distance perspectives and where the stakes are high, as on large multi-national construction projects for example. Appreciation of cultural contexts is essential to prevent latent conflicts from festering such that they become manifest only when they have, effectively, reached the stage of dispute and are thus likely to have destructive effects. Such situations are more likely to arise in cases that involve actors from cultures in which the preservation of (overt) harmonious relationships is viewed as important - the more collectivist and higher power distance cultures.

Although research has portrayed Eastern cultures as being collectivist and high power distance (Smith, 2002; Vertinsky 
et al., 1990), they seem subject to quite rapid change in certain behaviour. According to Cheung and Chuah (1999)

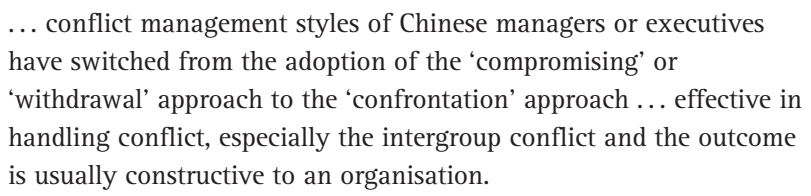

This, however, contrasts with the finding of Tang and Kirkbride (1986) that Chinese executives preferred to use the 'compromising' and 'withdrawal' approaches. The contrasting findings could be attributable to methods of research or/and temporal proximity of the reversion of sovereignty of Hong Kong to China. However, it is noteworthy that many firms remain owned by the same families or clans and '... autocracy in decision making and conflict resolution is still very much the norm' (Cheung and Chuah, 1999).

A study of a major hotel in Beijing found that both Chinese managers and operative staff did not want to accept responsibility, even if they had appropriate authority, but preferred to pass responsibility to expatriate managers (Mwaura et al., 1998). That finding raises questions over the effectiveness of empowerment in culturally ordered hierarchies, especially where persons from individualistic cultures head the structure (as in a multi-national hotel chain and on many major multi-national construction projects). This concerns both design of the management structure for effectiveness and efficiency and the potential for role conflict through persons failing to exercise appropriate positional power (French and Raven, 1959).

On construction projects, it is common for there to be two, sometimes quite enduring, causes of conflict. Due to the nature of TMOs, akin to matrix organisations, the potential for role conflicts is very high: any person is likely to be subject to incompatible role demands, or perceived expectations, from others on the project and stakeholders beyond the project's immediate boundary. The other common issue is competition for resources (aggregate demand for resources on the project exceeds current supply). Although competition is different from conflict, such immediate scarcities yield conflicts amongst interest groups - commonly addressed by a bargaining approach which, of course, may include a significant element of power invocation to achieve resolution of the conflict episode.

Clearly, many of the typologies of conflict denote categories that, in practice, are likely to become interactive in a conflict episode. An important component of endeavouring to manage conflict is recognition of the categories and manipulation of progression of the episode such that the category types likely to have destructive effects are avoided, minimised or terminated early and quickly so that the focus is on potentially productive effects. Minimising affective conflict (which would result in reduced progress, poorer decisions, reduced commitment, decreased cohesiveness and decreased empathy) focuses the conflicts that do arise (inevitably?) on cognitive elements (resulting in better decisions, increased commitment, increased cohesiveness, increased empathy and understanding) (Amason et al., 2000). This requires managers to ensure that (subordinate) groups remain focused on core issues and (through concentration on cognitive aspects and minimisation of affective aspects) problems can be identified and addressed quickly to arrive at good solutions. Primarily, proactive management is necessary to achieve such outcomes.

Within the domain of culture research, the analysis of individualism/collectivism (IC) into vertical and horizontal components is germane. IC is often adopted as a primary measure to distinguish the characteristic behaviours of people (Gomez et al., 2000; Wagner and Moch, 1986). IC is a bi-polar construct where an individualist considers his/her personal interests more important than the interests of a group. On the other hand, a collectivist values membership of a group and looks for benefits to the group even at the expense of his/her own personal interests (Hofstede, 1980, 1994b). Collectivists are members of very few in-groups and are highly loyal and positively disposed to other members; individualists may have loose membership of many in-groups but are tied to each one to a much lesser degree.

People in collectivist cultures favour in-group members but discriminate against out-group members (Triandis, 1995). Individualism is characterised as low concern for collectivity, coupled with low concern for in-group others. Both individualism and collectivism may be differentiated into vertical and horizontal components; horizontal components emphasise equality while vertical components emphasise hierarchy (Triandis and Gelfand, 1998). Vertical individualists stress competition and hedonism; horizontal individualists stress self-reliance. Vertical collectivists tend to be authoritarian and traditional, while horizontal collectivists stress sociability and interdependence.

Because the vertical scale items refer to work situations and the horizontal scale items primarily refer to non-work situations, one may speculate that the Chinese are becoming 'organizational individualists' even though they are still cultural collectivists in other domains ... (Chen et al., 1997).

A meta-analysis regarding the predictive power of IC on allocative behaviour demonstrates a need for an understanding of how to design management systems that are most effective, given any particular cultural setting (Sama and Papamarcos, 2000). From the perspective of conflict management, people from individualistic cultures prefer dominating or obliging styles while those from collectivistic cultures adopt avoiding or integrating styles (Kaushal and Kwantes, 2006). However, traditional Chinese organisations are hierarchical and large power distance with centralised and autocratic decision making. Internally at least, they promote more assertive and less accommodative styles of dealing with conflict; externally, cultural and institutional factors (including face and guanxi) dominate (Earley, 1997). Thus, overtly

... people from collectivistic cultures ... [are] ... more likely to utilize the avoidance conflict management strategy with the goal of maintaining a positive relationship ... collectivistic cultures tend to emphasize harmony (high power distance) ... (Kaushal and Kwantes, 2006).

In selecting persons and organisations with whom to conduct transactions, there is much evidence indicating that compatibility is essential. One element is minimisation of cultural distance (Fellows and Liu, 2006), which may not be 
feasible for multi-national construction projects; the other is to secure inter-culturally competent partners who have the ability to think and act in ways that are appropriate to the cultures involved, both individually and in combination.

Such inter-cultural competence is more likely among actors who are adventurist - those who desire and explore new situations that are then considered to be challenging (and thus positivised) rather than threatening (emphasising negative possibilities). Thus, adventurism is conducive to (Euwema and van Emmerik, 2007)

Cultural empathy ... the ability to empathize with the feelings, thoughts and behaviors of members of different cultural groups ... related with extraversion, agreeableness and intellectual autonomy. Agreeableness is also a key component of cooperative behaviours ..., and intellectual autonomy with creative problem solving ... expect that this cultural empathy is associated with cooperative approaches in conflict management.

\section{CONCLUSION}

The essence appears to be selecting appropriate participants with cultural empathy to accept different value structures and procedural systems. Furthermore, it is important to ensure that their behaviour will adhere to pursuit of the value structure established for the project and its realisation, and that changes will occur only through informed, reasoned and accepted dynamism - from a collaborative perspective rather than the usual self-oriented and opportunistic exercising of power.

Hence, in selecting others with whom to embark on multinational projects, two related personality factors seem important - adventurism and cultural empathy. Adventurist persons regard differences as challenges rather than threats, therefore fostering the positive potential of competition and conflict. Cultural empathy invokes sensitivity to others and preparedness and ability to operate in differing environments by accepting and responding positively to enhance performance in a situational/contingent way. Combination of these two traits should yield significant positive outcomes on multi-national projects through building motivation, trust and willingness to cooperate.

Successful management of conflict must be sensitive to the objectives of the participants, their behavioural characteristics and preferences/norms (derived from culture) and, in so doing, overtly acknowledge the existence of conflicts as early as possible so that management of conflict is both active and appropriate.

It seems helpful to consider any (array of) conflict episode(s) in terms of sources (persons), causes (reasons), mechanisms (processes) and effects (outcomes/consequences).

(a) The persons are those individuals - whether as themselves or as agents of organisations (and, if so, the organisations too) who are involved in the conflict episode.

(b) The reasons may be classified as personal (which give rise to affective conflict) or technical (which yield cognitive conflict). Given the almost universal environment of market capitalism, the technical causes may be classified as business (generic objectives and activities in the market capitalist environment) or technological (the particular activities of the (sub-)industry).

(c) The mechanisms concern how the episode arises, progresses and terminates.

(d) The effects are what remain after termination of the episode regarding people, organisations, business and technology.

\section{PROSPECTIVE RESEARCH AGENDA}

There is a strong need to clearly define the roles and responsibilities of participants in the different organisations in joint ventures to achieve a 'no-blame, truthful, reliable and responsive culture within the construction industry' (Swan et al., 2008). The analysis and conclusions presented here indicate that a number of important gaps exist for which the following research agenda is suggested.

(a) Identification and appropriate quantifications of the sources, causes and effects of conflict episodes, acknowledging that these may be culturally specific and related to particular cultural contexts.

(b) Research into relationships between cultural distances between participants and the incidences, natures and effects of conflicts/disputes.

(c) Measurement of compatibility amongst project participants, potentially as an index, with respect to participant selection to minimise negative conflict.

(d) Research into the hierarchy of performance criteria in various cultures with attention to the values espoused by the participants.

(e) Investigation of the evolution (changes) in performance criteria for projects during project realisation and of their consequences for stakeholders.

\section{REFERENCES}

Amason AC, Hochwarter WA, Thompson KR and Harrison AW (2000) Conflict: an important dimension in successful management teams. Organizational Dynamics 24(2): 20-35.

Ansari MA, Baumgartel H and Sullivan G (1982) The personalorganisational climate fit and managerial success. Human Relations 35(13): 1159-1178.

$\mathrm{Au}$ KY (2000) Inter-cultural variation as another construct of international management: a study based on secondary data of 42 countries. Journal of International Management 6(3): 217-238.

Bachmann R (2001) Trust, power and control in transorganizational relations. Organization Studies 22(2): 337-367.

Baiden BK, Price ADF and Dainty ARJ (2006) The extent of team integration within construction projects. International Journal of Project Management 24(1): 13-23.

Buckley PJ and Casson M (1995) A theory of cooperation in international business. In International Management: A Reader (Ghauri PN and Prasad SB (eds)). Dryden Press, London, pp. 126-145.

Buss DM, Abbott M, Alois A et al. (1990) International preferences in selecting mates: a study of 37 cultures. Journal of Cross-Cultural Psychology 21(1): 5-47.

CAG (Comptroller and Auditor General) (2001) Modernising Construction. National Audit Office, London.

Cameron KS and Quinn RE (1999) Diagnosing and Changing Organizational Culture. Addison-Wesley Longman, Reading, MA. 
CCC (Chinese Culture Connection, a team of 24 researchers) (1987) Chinese values and the search for culture-free dimensions of culture. Journal of Cross-Cultural Psychology 18(2): 143-164.

Chan DKS, Gelfand MJ, Triandis HC and Tzeng $O$ (1996) Tightness-looseness revisited: some preliminary analyses from Japan and the United States. International Journal of Psychology 31(1): 1-12.

Chatman JA and Jehn KA (1994) Assessing the relationship between industry characteristics and organisational culture: how different can you be? Academy of Management Review 37(3): 522-553.

Chen CC, Meindl JR and Hunt RG (1997) Testing the effects of vertical and horizontal collectivism: a study of allocation preferences in China. Journal of Cross-Cultural Psychology 28(1): 44-70.

Cheung CC and Chuah KB (1999) Conflict management styles in Hong Kong industries. International Journal of Project Management 17(6): 393-399.

Clegg SR (1992) Contracts cause conflicts. In Construction Conflict Management and Resolution (Fenn P and Gameson R (eds)). E \&t FN Spon, London, pp. 128-144.

Cox A (1999) Power, value and supply chain management. Supply Chain Management 4(4): 167-175.

Dainty ARJ, Bryman A, Price ADF et al. (2005) Project affinity: the role of emotional attachments in construction projects. Construction Management and Economics 23(3): 241-244.

Davis SM (1985) Culture is not just an internal affair. In Gaining Control of the Corporate Culture (Kilmann RH, Saxton MJ, Serpa A and Associates (eds)). Jossey-Bass, San Francisco, CA, USA, pp. 137-147.

Deal TE and Kennedy AA (1982) Corporate Cultures: The Rites and Rituals of Corporate Culture. Addison-Wesley, Reading, MA.

Deutsch M (1973) The Resolution of Conflict: Constructive and Destructive Processes. Yale University Press, New Haven, CT.

Doney PM, Cannon JP and Mullen MR (1998) Understanding the influence of national culture on the development of trust. Academy of Management Review 23(3): 601-620.

Earley PC (1997) Face, Harmony and Social Structure. Oxford University Press, Oxford.

Egan J (1998) Rethinking Construction. HMSO, London.

Euwema MC and van Emmerik IJH (2007) Intercultural competences and conglomerated conflict behaviors in intercultural conflicts. International Journal of Intercultural Relations 31(4): 427-441.

Fellows RF, Langford DA, Newcombe R and Urry SA (2002) Construction Management in Practice, 2nd edn. Blackwell, Oxford.

Fellows RF and Liu AMM (2006) Construction projects as joint ventures: issues of culture and risk. Proceedings of Second International Conference on Multi-National Joint Ventures for Construction Works, Hanoi, 71-83.

Fenn P (2008) Conflict management and dispute resolution. In Commercial Management of Projects. Defining the Discipline (Lowe D and Leiringer R (eds)). Blackwell Publishing, Oxford, pp. 234-269.

Fisher R and Ury W (1991) Getting to Yes: Negotiating Agreement without Giving in, 2nd edn. Penguin, New York.

French JRP and Raven B (1959) The bases of social power. In Studies in Social Power (Cartwright D (ed.)). Institute for Social Research, Ann Arbour, MI, pp. 150-167.
Gomez C, Kirkman BL and Shapiro DL (2000) The impact of collectivism and in-group/out-group membership on the generosity of team members. Academy of Management Journal 43(6): 1097-1100.

Green SD and Popper PA (1990) Value Engineering: The Search for Unnecessary Cost. Chartered Institute of Building, Ascot, Occasional Paper No. 39.

Green SD and Siminster SJ (1999) Modelling client business processes as an aid to strategic briefing. Construction Management and Economics 17(1): 63-76.

Hagen JM and Choe S (1998) Trust in Japanese interfirm relations: institutional sanctions matter. The Academy of Management Review 23(3): 589-600.

Harris LC and Ogbonna E (2002) The unintended consequences of cultural interventions: a study of unexpected outcomes. British Journal of Management 13(1): 31-49.

Helmreich RL and Merritt AC (1998) Culture at Work in Aviation and Medicine: National, Organizational and Professional Influences. Ashgate, Aldershot.

Herzberg F, Mausner B and Bloch Snyderman B (1967) The Motivation to Work, 2nd edn. Wiley, New York.

Hofstede GH (1980) Culture's Consequences: International Differences in Work-related Values. Sage, Beverley Hills, CA.

Hofstede GH (1994a) The business of international business is culture. International Business Review 3(1): 1-14.

Hofstede GH (1994b) Cultures and Organizations: Software of the Mind. Harper Collins, London.

Hofstede GH (2001) Culture's Consequences: Comparing Values, Behaviors, Institutions, and Organizations Across Nations, 2nd edn. Sage, Thousand Oaks, CA.

Hofstede GH, Neuijen B, Ohayv DD and Sanders G (1990) Measuring organisational cultures: a qualitative and quantitative study across twenty cases. Administrative Science Quarterly 35(2): 286-316.

Hood JN and Koberg CS (1991) Accounting firm cultures and creativity among accountants. Accounting Horizons 5(3): 12-19.

Hoppe MA (1990) A Comparative Study of Country Elites: International Differences in Work-related Values and Learning and Their Implications for Management Training and Development. Doctoral thesis, University of North Carolina.

House RJ, Hanges P, Ruiz-Quintanailla SA, et al. (1999) Cultural influences on leadership and organisations: project GLOBE. In Advances in Global Leadership, Vol. 1 (Mobley WF et al. (eds)). JAI Press, Stamford, CT, pp. 171-233.

Ireland P (2004) Managing appropriately in construction power regimes: understanding the impact of regularity in the project environment. Supply Chain Management 9(5): 372-382.

Kashima Y, Yamaguchi S, Kim U, et al. (1995) Culture, gender and self: a perspective from individualism-collectivism research. Journal of Personality and Social Psychology 69(5): 925-937.

Kaushal R and Kwantes CT (2006) The role of culture and personality in choice of conflict management strategy. International Journal of Intercultural Relations 30(5): 579-603.

Kelly J, Male S and Graham D (2004) Value Management of Construction Projects. Blackwell Science, Oxford.

Langford D and Murray M (2008) Procurement in the context of commercial management. In Commercial Management of 
Projects. Defining the Discipline (Lowe D and Leiringer R (eds)). Blackwell Publishing, Oxford, pp. 72-92.

Latham Sir M (1994) Constructing the Team. HMSO, London.

McKenna E (2000) Business Psychology and Organisational

Behaviour: A Student's Handbook, 3rd edn. Psychology Press, Hove.

McSweeney B (2002) Hofstede's model of national cultural differences and their consequences: a triumph of faith $-\mathrm{a}$ failure of analysis. Human Relations 55(1): 89-118.

Meek VL (1988) Organisational culture: origins and weaknesses. Organisational Studies 9(4): 453-473.

Mwaura G, Sutton J and Roberts D (1998) Corporate and national culture - an irreconcilable dilemma for the hospitality manager? International Journal of Contemporary Hospitality Management 10(6): 212-220.

Nicolini D (2002) In search of 'project chemistry'. Construction Management and Economics 20(2): 167-177.

Noorderhaven NG and Tidjani B (2001) Culture, governance and economic performance: an explorative study with a special focus on Africa. International Journal of Cross-Cultural Management 1(1): 31-52.

Oliver C (1997) Sustainable competitive advantage: combining institutional and resourced-based views. Strategic Management Journal 18(9): 697-173.

Ott JS (1989) The Organisational Culture Perspective. Brooks/ Cole, Pacific Grove, CA.

Ouchi W (1981) Theory Z: How American Business can meet the Japanese Challenge. Addison-Wesley, Reading, MA.

Parfitt MK and Sanvido VE (1993) Checklist of critical success factors for building projects. Journal of Management in Engineering 9(3): 243-249.

Pettigrew AM (1979) On studying organisational cultures. Administrative Science Quarterly 24(4): 570-581.

Pinto J and Slevin D (1988) Critical success factors across the project life cycle. Project Management Journal 19(3): 67-74.

Pondy LR (1967) Organizational conflict: concepts and models. Administrative Science Quarterly 12(2): 296-320.

Quinn RE (1988) Beyond Rational Management: Mastering the Paradoxes and Competing Demands of High Performance. Jossey-Bass, San Francisco, CA.

Reynolds PD (1986) Organisational culture as related to industry, position, and performance: a preliminary report. Journal of Management Studies 23(3): 333-345.

Robbins SP (1974) Managing Organisational Conflict. PrenticeHall, New York.

Robbins SP (1984) Essentials of Organizational Behavior. Prentice-Hall, Englewood Cliffs, NJ.

Roberts K and Boyacigiller N (1984) Cross-national organizational research: the grasp of the blind man. In Research in Organizational Behavior, Vol. 6 (Staw BM and Cummings LL (eds)). JAI Press, Stanford, CT, pp. 423-497.

Rooke J, Seymour DE and Fellows RF (2003) The claims culture; a taxonomy of attitudes in the industry. Construction Management and Economics 21(2): 167-174.

Rooke J, Seymour DE and Fellows RF (2004) Planning for claims: an ethnography of industry culture. Construction Management and Economics 22(6): 655-662.

Sama LM and Papamarcos SD (2000) Hofstede's i-c dimension as predictive of allocative behaviors: a meta analysis. International Journal of Value-Based Management 13(2): 173-188.
Sathe V (1983) Implications of corporate culture: a manager's guide to action. Organisational Dynamics 12(2): 5-23.

Schein EH (1985) Organisational Culture and Leadership. Jossey-Bass, San Francisco, CA.

Schmidt WH (1974) Conflict: a powerful process for (good or bad) change. Management Review 63(12): 4-10.

Schneider WE (2000) Why good management ideas fail: the neglected power of organizational culture. Strategy and Leadership 28(1): 24-29.

Schwartz SH and Sagie G (2000) Value consensus and importance: a cross-national study. Journal of CrossCultural Psychology 31(4): 465-497.

Sherif M (1967) Group Conflict and Co-operation: Their Social Psychology. Routledge and Kegan Paul, London.

Sheth JN and Parvatiyar A (1992) Towards a theory of business alliance formation. Scandinavian International Business Review 1(3): 71-87.

Singelis TM (1994) The measurement of independent and interdependent self-construals. Personality and Social Psychology Bulletin 20(5): 580-591.

Smith PB (2002) Culture's consequences: something old and something new. Human Relations 55(1): 119-135.

Swan W, Mcdermott P and Khalfan M (2008) Trust and commercial managers: influences and impacts. In Commercial Management of Projects. Defining the Discipline (Lowe D and Leiringer R (eds)). Blackwell Publishing, Oxford, pp. 172-191.

Tang SFY and Kirkbride PS (1986) The Development of Conflict Handling Skills in Hong Kong: Some Cross Cultural Issues. City Polytechnic of Hong Kong, Working Paper No. 7.

Thomas KW (1992) Conflict and negotiation processes in organizations. In Handbook of Industrial and Organisational Psychology (Dunnette MD and Hough LM (eds)). Consulting Psychology Press, Palo Alto, CA.

TIHR (Tavistock Institute of Human Relations) (1966) Interdependence and Uncertainty: A Study of the Building Industry. Tavistock Publications, London.

Triandis HC (1995) Individualism and Collectivism. Westview Press, Boulder, CO.

Triandis HC and Gelfand MJ (1998) Converging measurement of horizontal and vertical individualism and collectivism. Journal of Personality and Social Psychology 74(1): 118-128.

Trompenaars F and Hampden-Turner C (1997) Riding the Waves of Culture: Understanding Cultural Diversity in Business, 2nd edn. Nicholas Brealey, London.

van De Vliert E (1998) Conflict and conflict management. In Handbook of Work and Organizational Psychology, Volume 3: Personnel Psychology, 2nd edn (Drenth PJD et al. (eds)). Psychology Press, Hove, pp. 351-376.

Vertinsky I, Tse DK, Wehrung DA and Lee K-H (1990) Organizational design and management norms: a comparative study of managers' perceptions in the People's Republic of China, Hong Kong and Canada. Journal of Management 16(4): 853-867.

Wagner JA III and Moch MK (1986) Individualism-collectivism: concept and measure. Group and Organization Studies 11(3): 280-305.

Wallach EJ (1983) Individuals and organisations: the cultural match. Training and Development Journal 37(2): 29-36.

Weeks J and Gulunic C (2003) A theory of the cultural evolution of the firm: the intra-organizational ecology of memes. Organization Science 24(8): 1309-1352. 
Westerveld E (2003) The project excellent model: linking success criteria and critical success factors. International Journal of Project Management 21(6): 411-418.

Wood G and McDermott P (1999) Looking for trust in construction: an interim view. In Profitable Partnering in
Construction Procurement. (Ogunlana SO (ed.)). E \& FN Spon, London, pp. 107-116.

Yuen C-CE (1992) Conflict-handling processes. In Organisational Behaviour: Southeast Asian Perspectives (Westwood RI (ed.)). Longman Asia, Hong Kong, pp. 362-379.

\section{What do you think?}

To discuss this paper, please email up to 500 words to the editor at journals@ice.org.uk. Your contribution will be forwarded to the author(s) for a reply and, if considered appropriate by the editorial panel, will be published as a discussion in a future issue of the journal.

Proceedings journals rely entirely on contributions sent in by civil engineering professionals, academics and students. Papers should be 2000-5000 words long (briefing papers should be 1000-2000 words long), with adequate illustrations and references. You can submit your paper online via www.icevirtuallibrary.com/content/journals, where you will also find detailed author guidelines. 